\title{
Developing fragility functions for the areas affected by the 2009 Samoa earthquake and tsunami
}

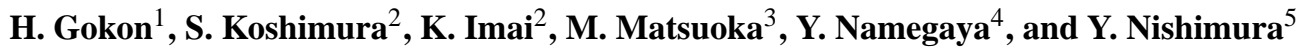 \\ ${ }^{1}$ Graduate School of Engineering, Tohoku University, Sendai, Japan \\ ${ }^{2}$ International Research Institute of Disaster Science, Tohoku University, Sendai, Japan \\ ${ }^{3}$ Interdisciplinary Graduate School of Science and Engineering, Tokyo Institute of Technology, Yokohama, Japan \\ ${ }^{4}$ Geological Survey of Japan, National Institute of Advanced Industrial Science and Technology, Tsukuba, Japan \\ ${ }^{5}$ Institute of Seismology and Volcanology, Graduate School of Science, School of Science, Hokkaido University, \\ Sapporo, Japan \\ Correspondence to: H. Gokon (gokon@geoinfo.civil.tohoku.ac.jp)
}

Received: 7 November 2013 - Published in Nat. Hazards Earth Syst. Sci. Discuss.: 2 January 2014

Revised: 27 October 2014 - Accepted: 27 October 2014 - Published: 4 December 2014

\begin{abstract}
Fragility functions in terms of flow depth, flow velocity and hydrodynamic force are developed to evaluate structural vulnerability in the areas affected by the 2009 Samoa earthquake and tsunami. First, numerical simulations of tsunami propagation and inundation are conducted to reproduce the features of tsunami inundation. To validate the results, flow depths measured in field surveys and waveforms measured by Deep-ocean Assessment and Reporting of Tsunamis (DART) gauges are utilized. Next, building damage is investigated by visually interpreting changes between pre- and post-tsunami high-resolution satellite images. Finally, the data related to tsunami features and building damage are integrated using Geographic Information System (GIS), and tsunami fragility functions are developed based on the statistical analyses. From the developed fragility functions, we quantitatively understood the vulnerability of a coastal region in American Samoa characterized by steep terrains and ria coasts.
\end{abstract}

\section{Introduction}

On 29 September 2009 (UTC), an earthquake doublet of magnitudes 8.0 and 7.9 and a subsequent tsunami struck the Samoan Islands and Tonga (Beavan et al., 2010; Lay et al., 2010). After the event, an International Tsunami Survey Team (ITST) was deployed, and the mechanism and impacts of this earthquake and tsunami have been studied in terms of geology, geophysics, seismology, sociology and engineering (Apotsos et al., 2011; Dudley et al., 2011; Jaffe et al., 2011; Lamarche, 2010; Okal et al., 2011; Roeber et al., 2010; vanZijlldeJong et al., 2011; Wilson et al., 2011). Okal et al. (2010) surveyed the tsunami run-up height at nearly 400 points, and found maximum run-up heights of $17.6 \mathrm{~m}$ at Poloa in American Samoa and $22.4 \mathrm{~m}$ at Tafahi in northern Tonga. The tsunami caused nearly 200 deaths in independent Samoa, American Samoa, and Tonga (Okal et al., 2010; Dudley et al., 2011).

To construct communities that will be resilient to destructive tsunami disasters, it is necessary to evaluate not only the mechanism and impacts of the disaster, but also the vulnerability of the coastal region. "Tsunami fragility functions" have been developed to evaluate the structural vulnerability of coastal communities to tsunami disasters, and have been tested on several tsunami events (Koshimura et al., 2009b, 2010; Mas et al., 2012; Porter et al., 2007; Reese et al., 2011; Suppasri et al.,2011, 2012, 2013). In recent studies, new approaches have been attempted to identify the relationship between the building damage and the features of tsunami inundation using a new statistical model (Charvet et al.,2014a, b; Leelawat et al., 2014).

Tsunami fragility functions express the relationship between the proportional damage to buildings, vegetation, or human life, and the tsunami-inundation features such as flow depth, current velocity and hydrodynamic force. These parameters are described quantitatively, making it possible 
to distinguish safe and potentially damaged zones. For the 2009 Samoa event, only Reese et al. (2011) have developed fragility functions using surveyed data. Fragility functions are developed probabilistically; to evaluate the vulnerability of affected areas more accurately, fragility functions should be proposed from several points of view.

The primary objective of this study is to develop tsunami fragility functions by integrating tsunami-inundation features with the spatial distribution of building damage using Geographic Information System (GIS). To derive the tsunami-inundation features, a detailed consideration of the tsunami-source model and numerical modeling of the tsunami inundation are conducted. Different grades of building damage are then interpreted using pre- and post-tsunami high-resolution satellite images. The tsunami-simulation and building-damage results are verified using field-survey data. Finally, the data related to tsunami features and building damage are integrated using GIS, and tsunami fragility functions are developed based on the statistical analyses.

\section{Post-tsunami field survey}

The study area encompassed Pago Pago, Leone, Poloa, and Amanave, American Samoa (Fig. 1). The types of structures in these areas are of wood and reinforced concrete (RC). Most of the buildings for residents are made of wood or masonry. Some churches and stores made of RC are also distributed in these areas. To investigate the actual building damages and tsunami characteristics, two field surveys were conducted, from 5 to 8 October 2009 and from 23 to 26 July 2010. In the first survey, flow depth, run-up height, and the inundation-area boundary were investigated, and each building in the affected areas was photographed using a GPS-equipped camera (Koshimura et al., 2010; Namegaya et al., 2010). In the second survey, precise land elevations were measured at Pago Pago, Leone, Poloa and Amanave, American Samoa, using a Magellan kinematic GPS (ProMark3). This kinematic GPS is highly accurate; if sufficient satellite coverage exists, positional accuracies of $\pm 20 \mathrm{~mm}$ (horizontal) and $\pm 30 \mathrm{~mm}$ (vertical) can be achieved. These data are used for verification of building damage interpreted using satellite images and the results of tsunami numerical simulations.

\section{Tsunami numerical simulations}

In contrast to most earthquakes, the 2009 Samoa earthquake involved the nearly simultaneous rupture of distinct faults with different geometries (Beavan et al., 2010; Lay et al., 2010). To understand the mechanism and impacts of the 2009 Samoa earthquake and tsunami, some researchers have conducted numerical simulations of the tsunami (Beavan et al., 2010; Didenkulova, 2013; Fritz et al., 2011; Roeber et al., 2010). Several hypotheses related to a series of earthquake

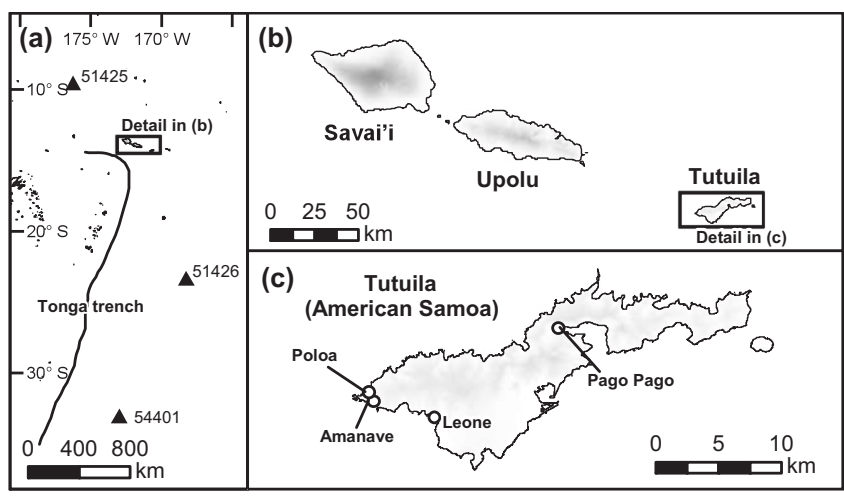

Figure 1. Study area (Pago Pago, Leone, Poloa and Amanave, American Samoa).

doublets have been proposed; however, no consensus has been reached regarding the earthquake seismology. Here, to understand the tsunami-generation mechanism and to reproduce the tsunami inundation of the coastal areas more precisely, two types of numerical simulations were conducted. First, numerical simulations of far-field tsunami propagation and reverse propagation were conducted, and the parameters of the ruptured faults were studied to reproduce the waveforms measured by the Deep-ocean Assessment and Reporting of Tsunamis (DART) network. Second, a tsunami inundation model was simulated to investigate the flow depth, current velocity and hydrodynamic force at Pago Pago, Leone, Poloa and Amanave, American Samoa.

\subsection{Far-field tsunami simulations}

To understand the tsunami-generation mechanism, the farfield tsunami propagation was simulated to reproduce the waveforms observed at DART gauges 51525, 51426 and 54401. The simulations were conducted according to the fault parameters of Beavan et al. (2010).

Initially, the fault-rupture areas related to tsunami generation were roughly estimated based on reverse-propagation analyses from each DART gauge. For outer-rise fault rupture, the rise time was fixed at $60 \mathrm{~s}$, and the time of rupture onset was assumed to be 17:48 on 29 September 2009 (UTC). For fault rupture on the interface, 20 sets of rise times ranging from 0 to $600 \mathrm{~s}$ at $30 \mathrm{~s}$ intervals were examined. The waveforms derived from these outer-rise and interface rise times were combined with different times of initial fault rupture ranging from $10 \mathrm{~min}$ before to $10 \mathrm{~min}$ after earthquake generation.

Despite numerous attempts using trial and error, the waveforms of the DART gauges located north and south of the epicenter could not be reproduced simultaneously using the original fault parameters of Beavan et al. (2010). To find a set of fault parameters that would simultaneously reproduce the northward and southward DART waveforms, the fault parameters were modified slightly based on the distribution of 
Table 1. Fault parameters used for far-field tsunami-propagation simulations.

\begin{tabular}{lccc}
\hline Fault parameters & Outer rise 1 & Outer rise 2 & Interface \\
\hline Lat $\left(^{\circ}\right)$ & -15.613 & -15.842 & -15.940 \\
Long $\left(^{\circ}\right)$ & -171.859 & -171.804 & -172.718 \\
Strike $\left(^{\circ}\right)$ & 330 & 330 & 175 \\
Dip $\left(^{\circ}\right)$ & 48 & 48 & 16 \\
Rake $\left(^{\circ}\right)$ & -150 & -90 & 85 \\
Length $(\mathrm{km})$ & 52.5 & 17.5 & 109 \\
Width $(\mathrm{km})$ & 45 & 45 & 90 \\
Area $\left(\mathrm{km}^{2}\right)$ & 2362.5 & 743.75 & 9810 \\
Depth $(\mathrm{km})$ & 13 & 13 & 18 \\
Slip $(\mathrm{m})$ & 8.6 & 8.6 & 4.1 \\
Time delay $(\mathrm{s})$ & 0 & 0 & -180 \\
Rise time $(\mathrm{s})$ & 60 & 60 & 480 \\
Rigidity $\left(\mathrm{Nm}{ }^{-2}\right)$ & $3.00 \times 10^{10}$ & $3.00 \times 10^{10}$ & $3.00 \times 10^{10}$ \\
Moment $(\mathrm{Nm})$ & $0.61 \times 10^{21}$ & $0.19 \times 10^{21}$ & $1.19 \times 10^{21}$ \\
$M_{\mathrm{w}}($ total $=8.13)$ & 7.79 & 7.45 & 7.98 \\
\hline
\end{tabular}

aftershocks during the week after the initial earthquake generation, while satisfying the coincidence of the seismic moment as shown in Table.

These simulations showed that the waveforms of the three DART gauges were reproduced well if the fault rupture on the interface started $3 \mathrm{~min}$ before the fault rupture on the outer rise. The simulated and observed DART waveforms are shown in Fig. 2.

\subsection{Tsunami-inundation simulations}

\subsubsection{Tsunami source model}

The fault proposed above accurately reproduced the DART waveforms, but did not accurately reproduce the tsunami characteristics such as flow depth in American Samoa. To reproduce the observed tsunami characteristics at Pago Pago, Leone, Poloa and Amanave, tsunami-inundation simulations were conducted according to the fault parameters of Beavan et al. (2010). The simulated tsunami waveforms at the DART gauges according to Beavan et al. (2010) and the corresponding fault parameters are shown in Table and Fig. 3. An example of a tsunami source model is shown in Fig. 4a.

\subsubsection{Digital bathymetry and topography grid model}

For the numerical simulation of tsunami inundation at Pago Pago, Leone, Poloa and Amanave, Tutuila, American Samoa, the model was based on a set of nonlinear shallow-water equations with bottom friction in the form of Manning's formula, according to land use. The equations were discretized according to the staggered leapfrog finite-difference scheme. To develop the computational grids for the numerical model, we used a digital-bathymetry grid derived from the GEBCO $30 \mathrm{~s}$ bathymetry data set and an NOAA-NGDC topography grid with a 3 arcsec digital elevation model (DEM) of American Samoa.

To model tsunami inundation in densely populated zones, we applied low resistance with a composite equivalent roughness coefficient based on the land use and building conditions (Aburaya and Imamura, 2002). In the equivalent roughness coefficient, we incorporated building density by generating building-footprint data from the pre-tsunami QuickBird satellite images acquired on 15 April 2007 and 24 September 2009.

\subsection{Verification of tsunami inundation simulation}

We modified the fault slip to reproduce the inundation-area boundary and flow depth at each locality. The minimum slip is $9.6 \mathrm{~m}$ at Pago Pago, and the maximum slip is $14.6 \mathrm{~m}$ at Amanave. The increment of slip in outer rise fault does not affect the total moment magnitude so much. The total moment magnitude changes from 8.15 to 8.21 as the slip increases from 9.6 to $14.6 \mathrm{~m}$. At Pago Pago, we measured several tsunami-inundation features, such as flow depth and runup height. These data were used to validate the numerical simulations based on Aida (1978). According to Aida (1978), the geometric mean $\mathrm{K}$ and geometric standard deviation $\kappa$ derived from surveyed data can be used to evaluate the reproducibility of numerical simulations of tsunami events.

Aida's $K$ and $\kappa$ are defined as follows:

$\log K=\frac{1}{n} \sum_{i=1}^{n} \log K_{i}$

$\log \kappa=\sqrt{\frac{1}{n} \sum_{i=1}^{n}\left(\log K_{i}\right)^{2}-(\log K)^{2}}$,

$K_{i}=\frac{R_{i}}{H_{i}}$,

where $R_{i}$ and $H_{i}$ are the measured and modeled values of inundation height/depth at point $i$, respectively. $K$ is defined as the geometrical mean of $K_{i}$ and $\kappa$ as the deviation or variance from $K$, and these indices are used as criteria to validate the model by comparing the modeled and measured tsunamis. For Pago Pago, $K=0.97$ and $\kappa=1.13$ were obtained. These values satisfy the adequacy criteria for tsunami numerical modeling established by the Japan Society of Civil Engineers $(0.95<K<1.05, \kappa<1.45)$. For Leone, Poloa and Amanave, due to the lack of measured points, the numerical simulation was validated based on the inundation-area boundaries measured in the field survey (Jaffe et al., 2010; Koshimura et al., 2009a). Examples of the simulated results in terms of flow depth are shown in Fig. 4b-e.

\section{Interpretation of building damage}

Building damage was interpreted visually using pre- and post-tsunami high-resolution satellite images in a GIS 


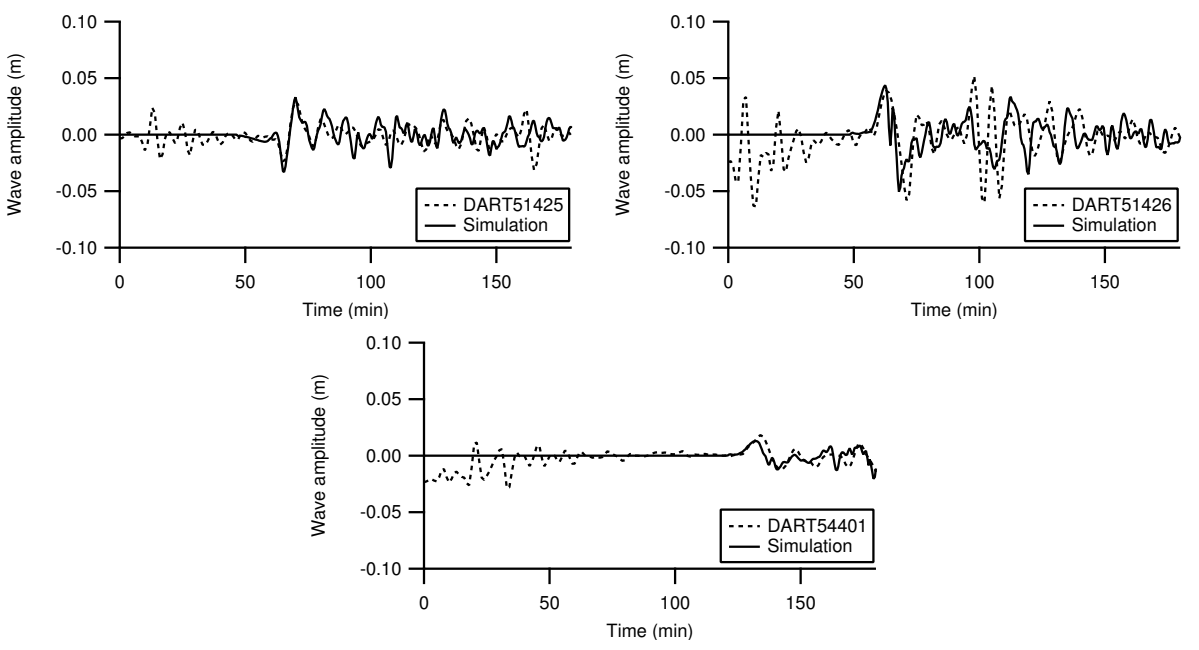

Figure 2. Comparison of the modeled waveforms from the tsunami propagation model and observed waveforms at the DART gauges.

Table 2. Fault parameters used for the numerical models of tsunami inundation (Beavan et al., 2010).

\begin{tabular}{lcc}
\hline Fault parameters & Outer rise & Interface \\
\hline Lat $\left(^{\circ}\right)$ & -15.542 & -15.940 \\
Lon $\left(^{\circ}\right)$ & -172.237 & -172.718 \\
Strike $\left(^{\circ}\right)$ & 352 & 175 \\
Dip $\left(^{\circ}\right)$ & 48 & 16 \\
Rake $\left({ }^{\circ}\right)$ & -41 & 85 \\
Length $(\mathrm{km})$ & 114 & 109 \\
Width $(\mathrm{km})$ & 28 & 90 \\
Depth $(\mathrm{km})$ & 13 & 18 \\
Slip $(\mathrm{m})(\mathrm{Pago}$ Pago/Amanave/Poloa/Leone) & $9.6 / 14.6 / 12.6 / 10.6$ & $4.1 / 4.1 / 4.1 / 4.1$ \\
Rigidity $\left(\mathrm{Nm}{ }^{-2}\right)$ & $3.00 \times 10^{10}$ & $3.00 \times 10^{10}$ \\
Moment $(\mathrm{Nm})$ & $0.82 \times 10^{21}$ & $1.19 \times 10^{10}$ \\
$M_{\mathrm{W}}$ & 7.9 & 8.0 \\
\hline
\end{tabular}

framework. An IKONOS satellite image acquired on 15 April 2007 and published by the GeoEye company in the US, and a QuickBird satellite image acquired on 24 September 2009 and published by the DigitalGlobe company in the US, were utilized as pre-event images. QuickBird satellite images acquired on 29 September 2009, 2 October 2009, and 2 November 2009 and published by the DigitalGlobe company were utilized as post-event images.

A total of 451 buildings in the inundated areas were investigated using remote-sensing technology and field surveys. In the remote-sensing approach, building damage was classified into four degrees: "Survived", "Major damage", "Collapsed", and "Washed away", according to Miura et al. (2006). Examples of these damage degrees in satellite images are shown in Fig. 5. These buildings are classified focusing on the changes in roofs between pre- and post-event satellite images. The criteria of the classification are as follows: (a) Survived: no change is observed in the roof; (b) Major damage: changes in small parts of the roof are observed; (c) Col- lapsed: changes in large parts of the roof are observed; and (d) Washed away: vanishing of the roof is observed. On the other hand, the field photos corresponding to these damage degrees are shown in Fig. 6. The criteria of building damage in the field survey are as follows: (a) Survived: no damage, or damage in the wall, but it does not extend to the structure, such as poles or joists; (b) Major damage: moderate structural damage, but it is not heavy; (c) Collapsed: heavy structural damage; and (d) Washed away: no structure is found. In the "Survived" degree, the wall might be destroyed; however, the structural part is not destroyed. Thus, a change in the roof is not observed in this degree. In the "Major damage" degree, the damage extended to the structural parts. Therefore, a small change in the roof is observed. In the "Collapsed" degree, most of the structures were destroyed, and a significant change in the roof is observed. In the "Washed away" degree, all of the structures have vanished. Therefore, it is difficult to investigate this damage degree in the field survey. In this case, a remote-sensing approach has an advantage, because 


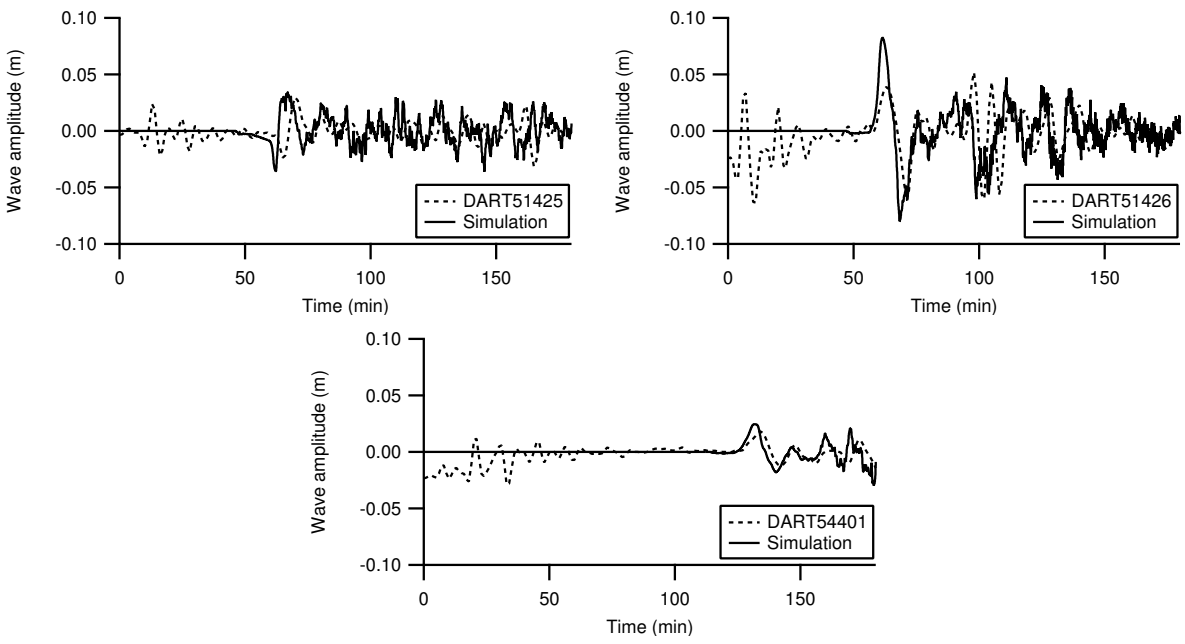

Figure 3. Comparison of the modeled waveforms from the tsunami propagation model and observed waveforms at the DART gauges. The tsunami source model is used for modeling tsunami inundation.

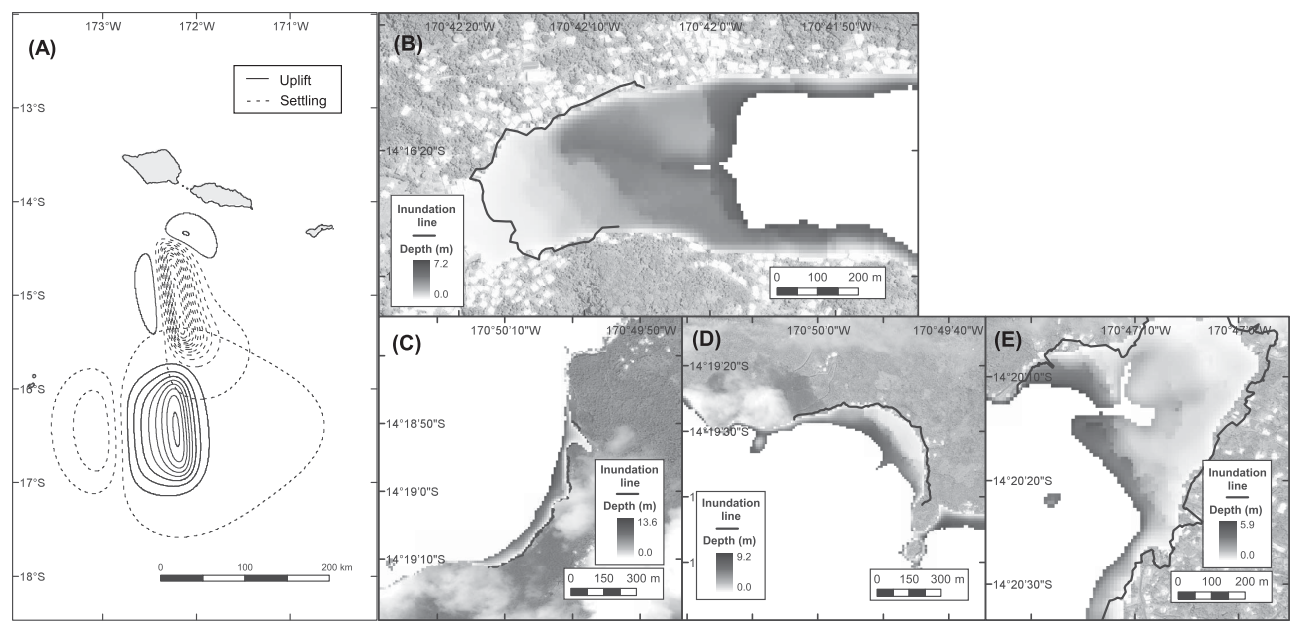

Figure 4. (a) Tsunami source model used for tsunami-inundation simulations and examples of tsunami inundation at (b) Pago Pago, (c) Poloa, (d) Amanave, and (e) Leone.

it is possible to compare the pre- and post-event situations in the images.

All of the classified results using remote-sensing technology were validated based on the photos taken using a GPS-equipped camera during the field survey. The damageinterpretation results are shown in Fig. 7 and Table 3. The "Survived" or "Washed away" buildings are interpreted almost perfectly. On the other hand, with respect to the "Major damage" or "Collapsed" buildings, the accuracies of classification decreased, because the satellite images captured from vertical direction sometimes could not comprehend the detailed structural damages.

These damage degrees should be compared with Reese et al. (2011). In Reese et al. (2011), building damage was classified into five degrees as follows: (a) $\mathrm{DS}_{0}$ : no damage; (b) $\mathrm{DS}_{1}$ : non-structural damage only; (c) $\mathrm{DS}_{2}$ : significant non- structural damage and minor structural damage; (d) $\mathrm{DS}_{3}$ : significant structural and non-structural damage; (e) $\mathrm{DS}_{4}$ : irreparable structural damage, and this will require demolition; and (f) $\mathrm{DS}_{5}$ : complete structural damage. Compared with the criteria of this study, the "Survived" degree corresponds to $\mathrm{DS}_{0}$ and $\mathrm{DS}_{1}$, "Major" corresponds to $\mathrm{DS}_{2}$ and $\mathrm{DS}_{3}$, and "Collapsed" corresponds to $\mathrm{DS}_{4}$ and $\mathrm{DS}_{5}$. The "Washed away" degree is included in $\mathrm{DS}_{5}$. On the other hand, the approach of this study utilized four damage degrees, because this was the maximum number of degrees we could classify using the satellite images. Even the spatial resolution of the satellite image is quite high; that is, up to $0.6 \mathrm{~m}$, images captured from the vertical direction do not show the detailed structural damages, because these are sometimes hidden by the roof. 


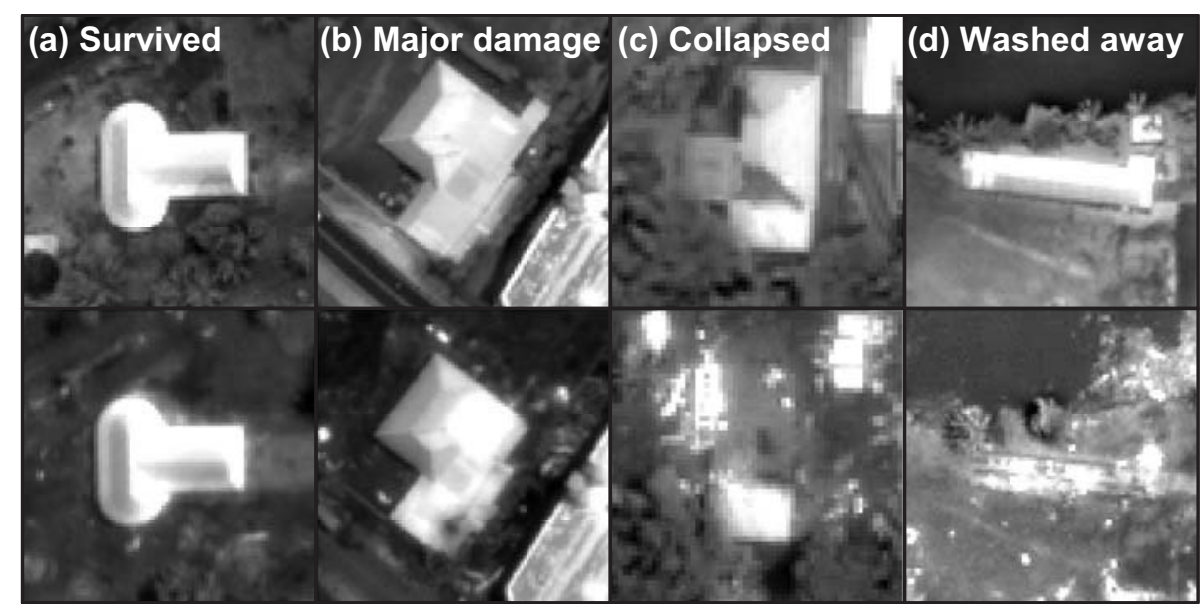

Figure 5. Classification criteria based on the remote sensing technology (upper photo: pre-tsunami; lower photo: post-tsunami).
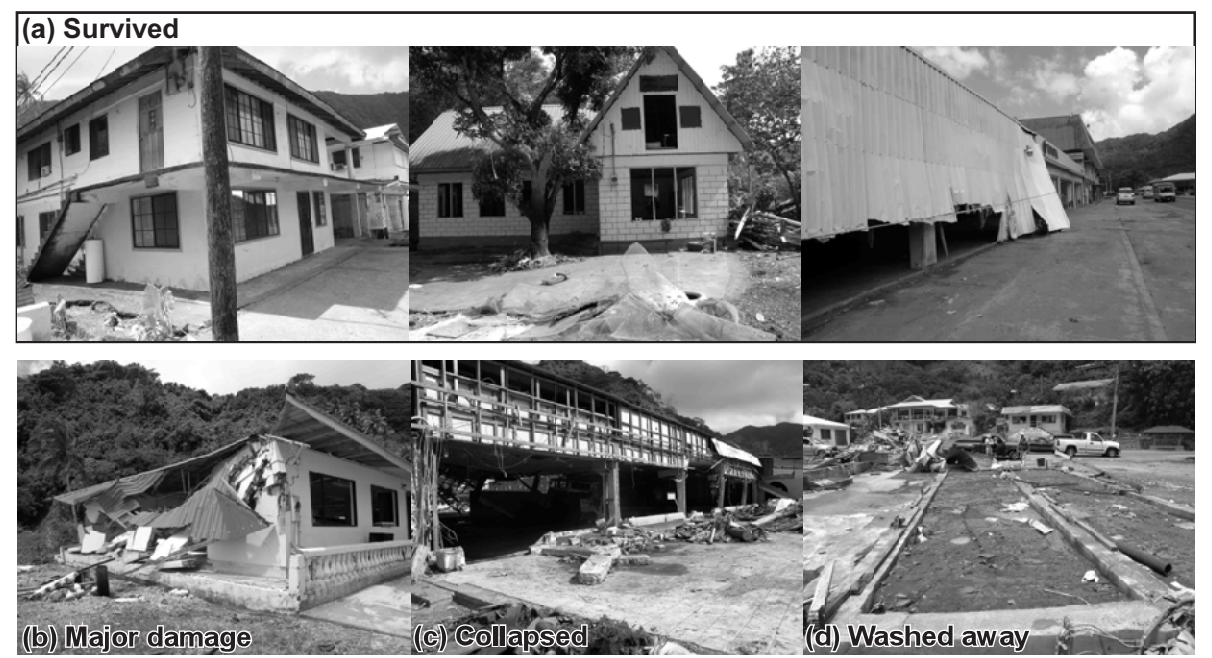

Figure 6. Classification criteria based on the field survey.

Table 3. Building-damage interpretation results

\begin{tabular}{lc}
\hline Damage category & $\begin{array}{c}\text { Number of buildings } \\
\text { (Pago Pago/Amanave/Poloa/Leone/Total) }\end{array}$ \\
\hline (a) Survived & $54 / 34 / 4 / 196 / 288$ \\
(b) Major damage & $14 / 2 / 0 / 12 / 28$ \\
(c) Collapsed & $7 / 3 / 1 / 7 / 18$ \\
(d) Washed away & $34 / 42 / 13 / 28 / 117$ \\
\hline
\end{tabular}

\section{Developing tsunami fragility functions}

\subsection{Tsunami fragility functions}

Fragility functions provide a new method for estimating structural damage and casualties due to tsunami events. These functions are developed through an integrated approach using numerical simulations of tsunami inundation and GIS analyses, and are expressed as the probabilities of structural damage or death rates with respect to the hydrodynamic features of tsunami inundation, such as flow depth, current velocity and hydrodynamic force (Koshimura et al., 2009b).

According to Koshimura et al. (2009b), fragility functions are defined by the following formulas:

$$
\begin{aligned}
P_{\mathrm{D}}(x) & =\Phi\left[\frac{x-\mu}{\sigma}\right] \\
& =\int_{-\infty}^{x} \frac{1}{\sqrt{2 \pi} \sigma} \exp \left(-\frac{(t-\mu)^{2}}{2 \sigma^{2}}\right) \mathrm{d} t, \\
P_{\mathrm{D}}(x) & =\Phi\left[\frac{\ln x-\lambda}{\xi}\right] \\
& =\int_{-\infty}^{x} \frac{1}{\sqrt{2 \pi} \xi t} \exp \left(-\frac{(\ln t-\lambda)^{2}}{2 \xi^{2}}\right) \mathrm{d} t,
\end{aligned}
$$




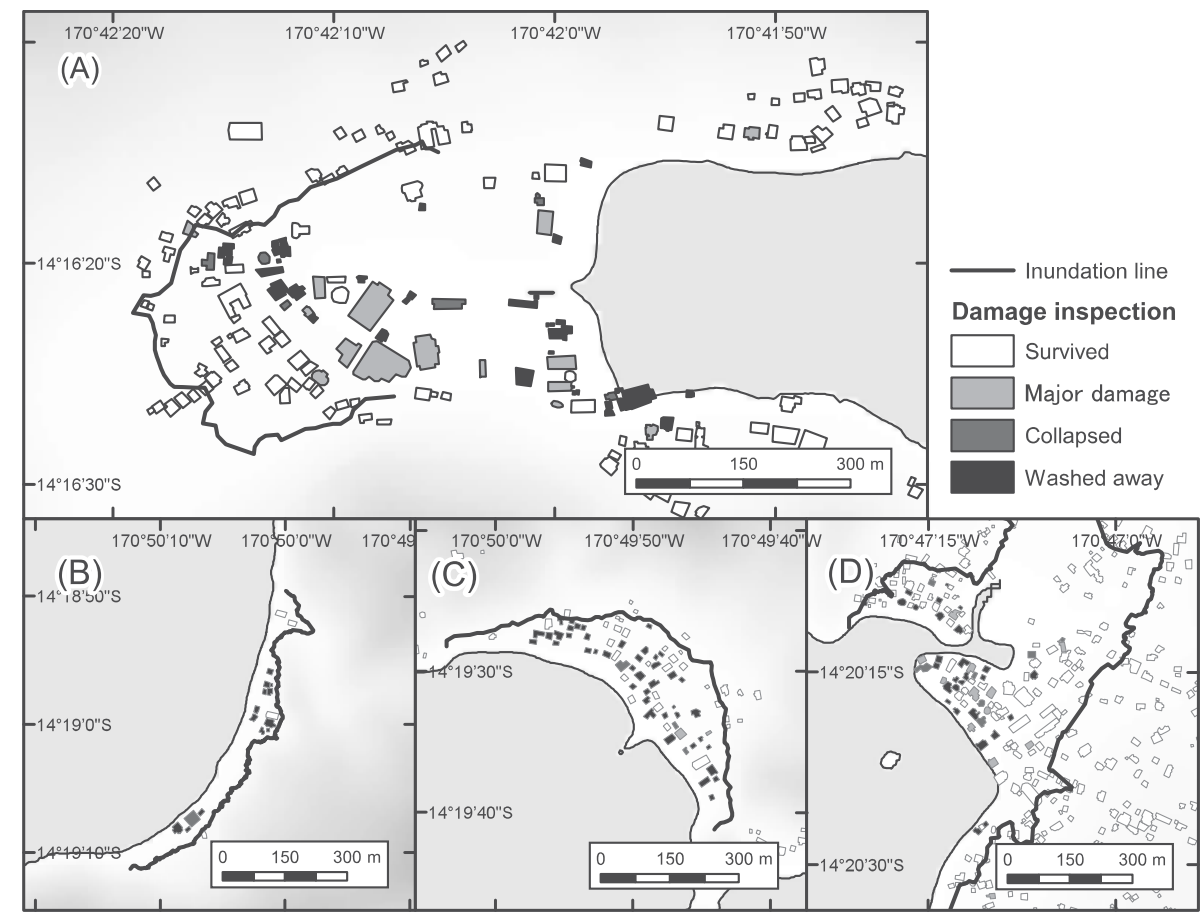

Figure 7. Interpreted building damage at (a) Pago Pago, (b) Poloa, (c) Amanave and (d) Leone.

where $\Phi$ is the standardized normal (lognormal) distribution function, $x$ is a hydrodynamic feature of the tsunami (e.g., flow depth, current velocity or hydrodynamic force), and $\mu$ and $\sigma(\lambda$ and $\xi)$ are the mean and standard deviation of $x(\ln x)$, respectively. The two statistical parameters for the fragility function, $\mu$ and $\sigma(\lambda$ and $\xi$ ), are obtained by plotting $x$ (or $\ln x$ ) against the inverse of $\Phi$ on normal or lognormal probability and performing least-squares fitting of this plot. Consequently, two parameters are derived by determining the intercept $(=\mu$ or $\lambda)$ and the slope $(=\sigma$ and $\xi)$ by the following formulas:

$x=\sigma \Phi^{-1}+\mu$

$\ln x=\xi \Phi^{-1}+\lambda$.

Throughout the regression analysis, the parameters shown in Table 4 were used to obtain the best fit for fragility functions with respect to the maximum flow depth $(\mathrm{m})$, maximum current velocity $\left(\mathrm{m} \mathrm{s}^{-1}\right)$ and maximum hydrodynamic force on structures per unit width $\left(\mathrm{kN} \mathrm{m}^{-1}\right)$. Here, the hydrodynamic force acting on a structure is defined as the drag force per unit of width:

$F=\frac{1}{2} C_{\mathrm{D}} \rho \mu^{2} D$

where $C_{\mathrm{D}}$ is the drag coefficient $\left(C_{\mathrm{D}}=1.0\right.$ for simplicity), $\rho$ is the density of water $\left(=1000 \mathrm{~kg} \mathrm{~m}^{-3}\right), \mu$ is the current velocity $\left(\mathrm{m} \mathrm{s}^{-1}\right)$, and $D$ is the flow depth (m).

To develop the tsunami fragility functions, the four damage levels were grouped into two classes, "Destroyed" and
"Non-destroyed". "Destroyed" buildings were defined as structurally damaged buildings, and included three damage levels: "Washed away", "Collapsed", and "Major damage". "Non-destroyed" buildings were defined as structurally nondamaged buildings that were classified as "Survived" in the building-damage interpretation. Because the number of buildings for developing fragility function was not statistical enough, fragility functions in terms of this damage class are developed.

The resulting fragility functions, which are presented in Fig. 8, show the relationships between damage probabilities and the hydrodynamic features of tsunami inundation in American Samoa.

\subsection{Discussion}

It is necessary to discuss the building features in the study area, because fragility functions strongly depend on the characteristics of the structures. In the study area, basically we could find residential buildings, commercial buildings, churches and Samoan-specific buildings for meeting. Residential buildings were made of woods, or woods with bricks. Commercial buildings, which could be found mainly in Pago Pago, were made of bricks or reinforced concrete (RC). Churches were made of reinforced concrete. Samoanspecific buildings for meeting that have simple structures made of poles and roofs could be seen in some parts of the islands. Most of the buildings in the study area were residential buildings; therefore, it could be inferred that the proposed 
Table 4. Fragility-function parameters obtained from the regression analysis. $R^{2}$ is the coefficient of determination obtained by least-squares fitting.

\begin{tabular}{lccccc}
\hline$x$ for fragility functions $P(x)$ & $\mu$ & $\sigma$ & $\lambda$ & $\xi$ & $R^{2}$ \\
\hline Flow depth $(\mathrm{m})$ & NA & NA & 1.17 & 0.69 & 0.89 \\
Current velocity $\left(\mathrm{m} \mathrm{s}^{-1}\right)$ & NA & NA & 0.54 & 1.65 & 0.73 \\
Hydrodynamic force per width $\left(\mathrm{kN} \mathrm{m}^{-1}\right)$ & NA & NA & 1.07 & 3.16 & 0.72 \\
\hline
\end{tabular}
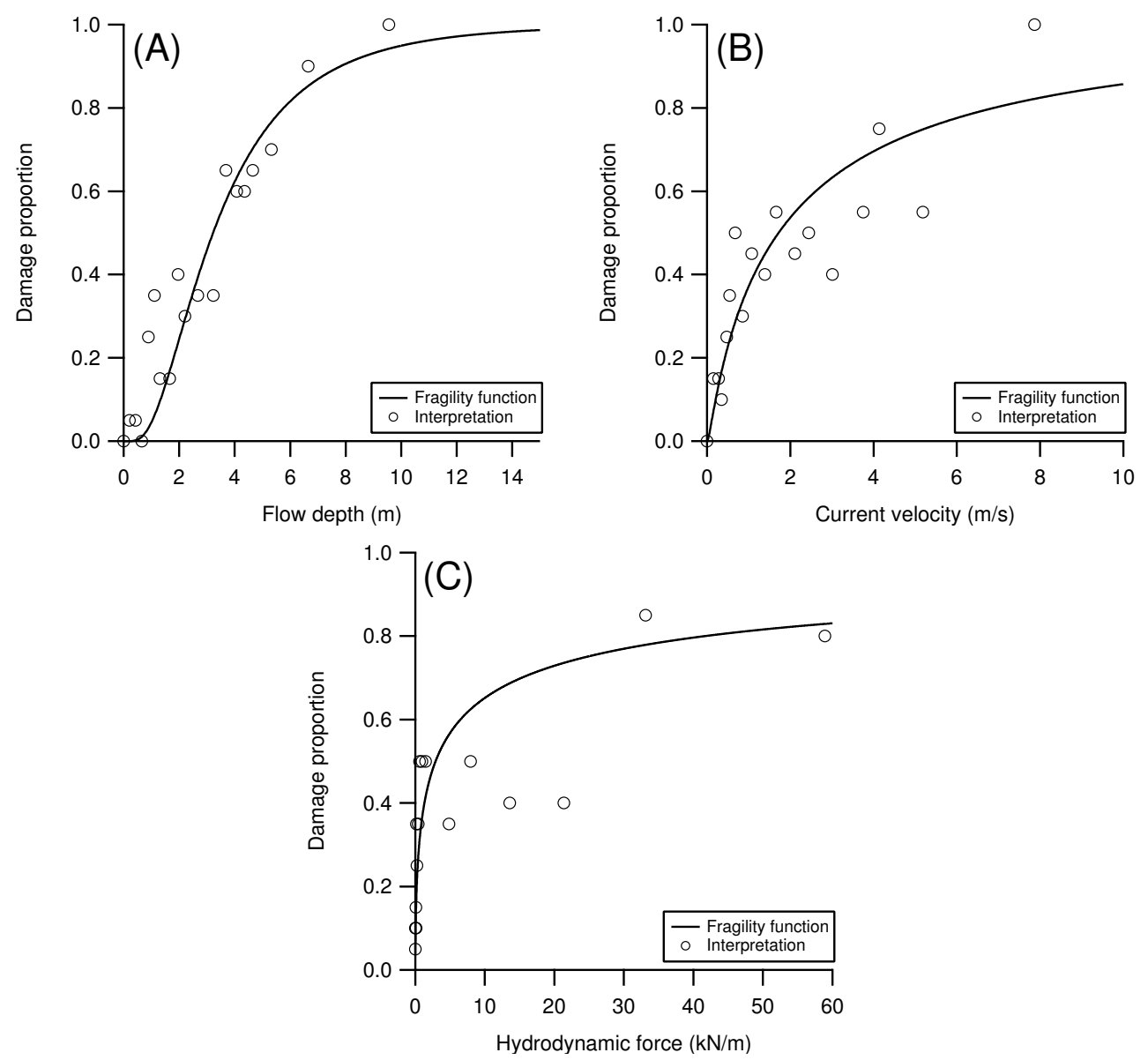

Figure 8. Fragility functions of (a) maximum flow depth, (b) maximum current velocity, and (c) maximum hydrodynamic force.

fragility functions were strongly influenced by the residential buildings made of woods or woods with bricks.

In Reese et al. (2011), fragility functions for different building types have been developed. However, in this study, it was not possible to separate the fragility functions based on the building types, because we could not investigate the types of washed-away buildings in the field survey. The number of washed-away buildings is dominant among the total number of damaged buildings we investigated, and it could not be ignored. Except for the washed-away buildings, the number of buildings for developing fragility functions decreases too much. Therefore, fragility functions were developed by mixing all the building types.
The fragility function of flow depth, shown in Fig. 8a, begins to increase as the flow depth exceeds $1 \mathrm{~m}$, and 80 to $90 \%$ of buildings are destroyed as the flow depth reaches $6 \mathrm{~m}$. This sudden rise in damage at a relatively low flow depth implies the vulnerability of this coastal region, which is likely to experience high water levels during tsunami events, due to its ria coasts.

The fragility function of current velocity, shown in Fig. 8b, rises steeply at a low current velocity of less than $2 \mathrm{~m} \mathrm{~s}^{-1}$ and rises gently at current velocities greater than $2 \mathrm{~m} \mathrm{~s}^{-1}$. The fragility function of hydrodynamic force, shown in Fig. 8c, also rises steeply at low hydrodynamic forces and rises gently at forces greater than $5 \mathrm{kN} \mathrm{m}^{-1}$. Compared to the flow-depth 
Table 5. Numbers of destroyed buildings estimated by the developed fragility functions.

\begin{tabular}{llccc}
\hline Study area & Tsunami feature & Estimated & Observed & Accuracy ratio \\
\hline \multirow{2}{*}{ Pago Pago } & Flow depth & 39.98 & & 0.71 \\
& Flow velocity & 40.74 & 55 & 0.74 \\
& Hydrodynamic force & 39.97 & & 0.73 \\
\hline \multirow{3}{*}{ Amanave } & Flow depth & 29.69 & & 0.42 \\
& Flow velocity & 28.81 & 47 & 0.37 \\
& Hydrodynamic force & 29.12 & & 0.39 \\
\hline \multirow{3}{*}{ Poloa } & Flow depth & 12.15 & & 0.85 \\
& Flow velocity & 11.74 & 14 & 0.81 \\
& Hydrodynamic force & 12.64 & & 0.89 \\
\multirow{2}{*}{ Leone } & Flow depth & 37.62 & & 0.75 \\
& Flow velocity & 55.59 & 47 & 0.85 \\
& Hydrodynamic force & 49.46 & & 0.95 \\
\hline \multirow{2}{*}{ Total } & Flow depth & 118.54 & & 0.62 \\
& Flow velocity & 136.88 & 163 & 0.81 \\
& Hydrodynamic force & 131.19 & & 0.76 \\
\hline
\end{tabular}

fragility function, these two functions show the variation among the interpreted points. A closer examination showed that the widely spread points represented buildings constructed of concrete or brick. Notably, churches and other simplified buildings consisting of poles and a roof, which can be found in many parts of the islands, were likely to survive tsunami inundation with high flow depth and flow velocity. These simplified buildings consisting of poles and a roof are used as assembly halls in the Samoan Islands region. The tsunami flow passes under the roof of these simplified buildings, leaving most buildings of this type intact.

To validate the fragility functions, the number of destroyed buildings in each study area was estimated by multiplying the fragility functions by the corresponding tsunami features at each building locality. These values were compared, and accuracy ratios were calculated for Pago Pago, Leone, Poloa and Amanave, as shown in Table 5. The fragility functions tended to underestimate the true damage by 10 to $20 \%$. These observations imply that buildings that are resilient to tsunami inundation, such as concrete buildings and Samoanspecific simplified buildings, caused the underestimation of the fragility functions. When these functions are applied in city planning, these features should be taken into account. In Pago Pago, Poloa, and Leone, the fragility functions of hydrodynamic force showed relatively greater accuracy. Therefore, the actual force that acts on the buildings should be given stronger consideration than the flow depth and current velocity. The accuracy ratios for Amanave were lower than those for the other areas, because the actual topographic conditions at Amanave differ from the DEM published by NOAA-NGDC, and we were unable to reproduce accurately the tsunami characteristic in this area.
At the end of this manuscript, it should be better to compare the fragility functions of this study with those of Reese et al. (2011). Reese et al. (2011) developed fragility functions based on the field survey. They investigated building damage with five degrees in a careful manner, and measured flow depth in the field survey. Finally, they were able to obtain fragility functions for several degrees and building types. However, there was room for improvement in the number of buildings dedicated to developing the fragility functions. At this point, our research could improve by applying the remote-sensing approach. In addition, we conducted tsunami numerical modeling, and developed the fragility functions of tsunami features in terms of current velocity and hydrodynamic force; and finally, we could develop the fragility functions from the other point of view, using the other tsunami features.

\section{Conclusions}

In this study, tsunami fragility functions in terms of flow depth, flow velocity and hydrodynamic force were developed for American Samoa by integrating tsunami numerical modeling with remote-sensing technology. The mechanism of tsunami generation was analyzed through numerical simulations. The waveforms measured by three DART gauges were reproduced well if the fault rupture on the interface was assumed to begin $3 \mathrm{~min}$ before the fault rupture on the outer rise. The tsunami-inundation distributions were then derived and validated using field-survey data. The spatial distribution of building damage was interpreted by comparing preand post-tsunami high-resolution satellite images of the affected areas. Finally, fragility functions were developed, and structural vulnerability in American Samoa was evaluated 
quantitatively. These functions were validated by estimating the number of destroyed buildings and comparing these estimates to the observed data.

These developed functions can be utilized to estimate the risks to tsunami in the other coastal areas in American Samoa. In addition, we can expect the areas with high potential to be devastated by the tsunami, by integrating the numerical modeling and the fragility functions.

On the other hand, there are some limitations in the fragility functions. For example, effects from floating debris and scourings are not taken into account in these fragility functions. Furthermore, building types, the age of buildings or floors of the buildings were mixed when developing the fragility functions. These limitations should be improved in future works.

Acknowledgements. This research was financially supported by the Industrial Technology Research Grant Program in 2008 (project ID 08E52010a) from the New Energy and Industrial Technology Development Organization (NEDO), by a Grant-in-Aid for Scientific Research (project number 22681025) from the Ministry of Education, Culture, Sports, Science and Technology (MEXT), by a Grant-in-Aid for JSPS fellows (project number 24.5839), and by the emergency tsunami survey.

Edited by: I. Didenkulova

Reviewed by: two anonymous referees

\section{References}

Aburaya, T. and Imamura, F.: The proposal of a tsunami run-up simulation using combined equivalent roughness, Annual Journal of Coastal Engineering, Japan Soc. Civil Eng., 49, 276-280, 2002 (in Japanese).

Aida, I.: Reliability of a tsunami source model derived from fault parameters, J. Phys. Earth, 26, 57-73, 1978.

Apotsos, A., Gelfenbaum, G., Jaffe, B., Watt, S., Peck, B., Buckley, M., and Stevens, A.: Tsunami inundation and sediment transport in a sediment-limited embayment on American Samoa, EarthSci. Rev., 107, 1-11, 2011.

Beavan, J., Wang, X., Holden, C., Wilson, K., Power, W., Prasetya, G., Bevis, M., and Kautoke, R.: Near-simultaneous great earthquakes at Tongan megathrust and outer rise in September 2009, Nature, 466, 959-963, 2010.

Charvet, I., Ioannou, I., Rossetto, T., Suppasri, A., and Imamura, F.: Empirical fragility assessment of buildings affected by the 2011 Great East Japan tsunami using improved statistical models, Nat. Hazards, 73, 951-973, 2014a.

Charvet, I., Suppasri, A., and Imamura, F.: Empirical fragility analysis of building damage caused by the 2011 Great East Japan Tsunami in Ishinomaki City using ordinal regression, and influence of key geographical features, Stochast. Environ. Res. Risk Assess., 28, 1853-1867, 2014b.

Didenkulova, I.: Tsunami runup in narrow bays: the case of Samoa 2009 tsunami, Nat. Hazards, 65, 1629-1636, 2013.
Dudley, W. C., Whitney, R., Faasisila, J., Jowitt, S. F. A., and ChanKau, M.: Learning from the victims: New physical and social science information about tsunamis from victims of the September 29, 2009 event in Samoa and American Samoa, Earth-Sci. Rev., 107, 201-206, 2011.

Fritz, H. M., Borrero, J. C., Synolakis, C. E., Okal, E. A., Weiss, R., Titov, V. V., Jaffe, B. E., Foteinis, S., Lynett, P. J., Chan, I., and Liu, P. L. F.: Insights on the 2009 South Pacific tsunami in Samoa and Tonga from field surveys and numerical simulations, Earth-Sci. Rev., 107, 66-75, 2011.

IOC, IHO and BODC: Centenary Edition of the GEBCO Digital Atlas, published on CD-ROM on behalf of the Intergovernmental Oceanographic Commission and the International Hydrographic Organization as part of the General Bathymetric Chart of the Oceans, British Oceanographic Data Centre, Liverpool, UK, 2003.

Jaffe, B. E., Gelfenbaum, G., Buckley, M. L., Watt, S., Apotsos, A., Stevens, A. W., and Richmond, B. M.: The limit of inundation of the 29 September 2009, tsunami on Tutuila, American Samoa, US Geological Survey, 2010.

Jaffe, B., Buckley, M., Richmond, B., Strotz, L., Etienne, S., Clark, K., Watt, S., Gelfenbaum, G., and Goff, J.: Flow speed estimated by inverse modeling of sandy sediment deposited by the 29 September 2009 tsunami near Satitoa, east Upolu, Samoa, Earth-Sci. Rev., 107, 23-37, 2011.

Koshimura, S., Nishimura, Y., Nakamura, Y., Namegaya, Y., Fryer, G. J., Akapo, A., Kong, L., and Vargo, D.: Field survey of the 2009 tsunami in American Samoa, Eos Trans. AGU, 90(52), Fall Meet. Suppl., Abstract U23F-07, 2009a.

Koshimura, S., Oie, T., Yanagisawa, H., and Imamura, F.: Developing Fragility Functions for Tsunami Damage Estimation using Numerical Model and Post-Tsunami Data from Banda Aceh, Indonesia, Coastal Eng. J., 51, 243-273, 2009b.

Koshimura, S., Kayaba, S., and Matsuoka, M.: Integrated Approach to Assess the Impact of Tsunami Disaster, Safety, Reliability and Risk of Structures, Infrastructures and Engineering Systems - edited by: Furuta, H., Frangopol, D. M., and Shinozuka, M., 2010.

Lamarche, G., Pelletier, B., and Goff, J.: Impact of the 29 September 2009 South Pacific tsunami on Wallis and Futuna, Mar. Geol., 271, 297-302, 2010.

Lay, T., Ammon, C. J., Kanamori, H., Rivera, L., Koper, K. D., and Hutko, A. R.: The 2009 Samoa-Tonga great earthquake triggered doublet, Nature, 466, 964-968, 2010.

Leelawat, N., Suppasri, A., Charvet, I. and Imamura, F.: Building damage from the 2011 Great East Japan tsunami: Quantitative assessment of influential factors - A new perspective on building damage analysis, Nat. Hazards, 73, 449-471, 2014.

Mas, E., Koshimura, S., Suppasri, A., Matsuoka, M., Matsuyama, M., Yoshii, T., Jimenez, C., Yamazaki, F., and Imamura, F.: Developing Tsunami fragility curves using remote sensing and survey data of the 2010 Chilean Tsunami in Dichato, Nat. Hazards Earth Syst. Sci., 12, 2689-2697, doi:10.5194/nhess-12-26892012, 2012.

Miura, H., Wijeyewickrema, A., and Inoue, S.: Evaluation of tsunami damage in the eastern part of Sri Lanka due to the 2004 Sumatra earthquake using remote sensing technique, Proc. 8th National Conference on Earthquake Engineering, Paper No.8, NCEE-856, 2006. 
Namegaya, Y., Koshimura, S., Nishimura, Y., Nakamura, Y., Gerard, F., Akapo, A., and Kong S. L.: rapid-response field survey of the 2009 Samoa earthquake tsunami in American Samoa, J. Japan Soc. Civil Eng., Ser. B2 (Coastal Engineering), 66, 13661370, 2010 (in Japanese).

Okal, E. A., Fritz, H. M., Synolakis, C. E., Borrero, J. C., Weiss, R., Lynett, P. J., Titov, V. V., Foteinis, S., Jaffe, B. E., Liu, P. L. F., and Chan, I.: Field survey of the samoa tsunami of 29 september 2009, Seismol. Res. Lett., 81, 4, 577-591, doi:10.1785/gssrl.81.4.577, 2010.

Okal, E. A., Borrero, J. C., and Chagu-Goffé, C.: Tsunamigenic predecessors to the 2009 Samoa earthquake, Earth-Sci. Rev. 107, 128-140, 2011.

Porter, K., Kennedy, R., and Bachman, R.: Creating fragility functions for performance based earthquake engineering, Earthquake Spec. 23, 471-489, 2007.

Reese, S., Bradley, B. A., Bind, J., Smart, G., Power, W., and Sturman, J.: Empirical building fragilities from observed damage in the 2009 South Pacific tsunami, Earth-Sci. Rev., 107, 156-173, 2011.

Roeber, V., Yamazaki, Y., and Cheung, K. F.: Resonance and impact of the 2009 Samoa tsunami around Tutuila, American Samoa, Geophys. Res. Lett. 37, L21604, doi:10.1029/2010GL044419, 2010.

Suppasri, A., Koshimura, S., and Imamura, F.: Developing tsunami fragility curves based on the satellite remote sensing and the numerical modeling of the 2004 Indian Ocean tsunami in Thailand, Nat. Hazards Earth Syst. Sci., 11, 173-189, doi:10.5194/nhess11-173-2011, 2011.
Suppasri, A., Mas, E., Koshimura, S., and Imai, K.: Developing Tsunami Fragility Curves From the Surveyed Data of the 2011 Great East Japan Tsunami in Sendai and Ishinomaki Plains, Coastal Eng. J., 54, 1250008, doi:10.1142/S0578563412500088, 2012.

Suppasri, A., Charvet, I., Imai, K., and Imamura, F.: Fragility curves based on data from the 2011 Great East Japan tsunami in Ishinomaki city with discussion of parameters influencing building damage, Earthquake Spec., doi:10.1193/053013EQS138M, in press, 2013.

US Geological Survey: Earthquake Hazards Program, Magnitude 8.1 - SAMOA ISLANDS REGION, available at: http://earthquake.usgs.gov/earthquakes/eqinthenews/2009/ us2009mdbi/\#details, 2009.

vanZijlldeJong, S. L., Dominey-Howes, D., Roman, C. E., Calgaro, E., Gero, A., Veland, S., Bird, D. K., Muliaina, T., TuilomaSua, D., and Afioga, T. L.: Process, practice and priorities key lessons learnt undertaking sensitive social reconnaissance research as part of an (UNESCO-IOC) International Tsunami Survey Team, Earth-Sci. Rev., 107, 174-192, 2011

Wilson, R. I., Dengler, L. A., Goltz, J. D., Legg, M. R., Miller, K. M., Ritchie, A., and Whitmore, P. M.: Emergency response and field observation activities of geoscientists in California (USA) during the September 29, 2009, Samoa Tsunami, Earth-Sci. Rev., 107, 193-200, 2011. 